\title{
Trabalhando com rememorações. Memória e história da reforma agrária do Banhado do Colégio: Camaquã, RS, Brasil - 1962-1972
}

Marluza Marques Harres*

Resumo: Neste texto apresento alguns resultados de uma pesquisa sobre a criação e o funcionamento do assentamento rural do Banhado do Colégio no início dos anos 1960. As reflexões de Maurice Halbwachs sobre memória coletiva estão destacadas e discutidas, pois orientam o trabalho com os depoimentos.

Abstract: In this text are presented some results of a research about the creation and development of the rural settlement known as "Banhado do Colégio", at the beginning of the $1960^{\text {th }}$. The ideas and reflections of Maurice Halbwachs on collective memory are emphasized and examined, because they guide this work based on oral history.

Palavras-chave: História oral. Memória coletiva. Assentamento rural.

Key words: Oral history. Collective memory. Rural settlement.

O início da década de 1960 no Brasil é recordado como um tempo marcado por grandes sonhos e profundas frustrações. Naquele contexto, algumas experiências transformadoras foram ensaiadas, especialmente impulsionadas pelo movimento reformista difundido em todo o país. Tenho estudado uma dessas experiências, investigando, particularmente, a reforma agrária do Banhado do Colégio, localidade situada no município de Camaquã, no Rio Grande do Sul. ${ }^{1}$ Criado no último ano do governo Leonel Brizola (1959-1962), este assentamento sobreviveu enfrentando a resistência dos fazendeiros e a ditadura militar instalada em 1964. Nesta comunicação, trabalho com alguns depoimentos de

Pesquisadora e professora do PPG em História da UNISINOS (RS).

E.mail: marluza@unisinos.br.

1 A reforma agrária do Banhado do Colégio foi o tema de minha tese de doutorado defendida em 2002 no PPG em História da UFRGS.

Estudos Ibero-Americanos. PUCRS, v. XXXII, n. 1, p. 127-141, junho 2006 
assentados utilizando as reflexões de Maurice Halbwachs sobre memória coletiva como ponto de partida.

A particularidade deste assentamento rural é que ele está inserido numa área de extrema fertilidade, pois é resultado da drenagem de um antigo banhado. Um banhado de deságüe que foi se constituindo ao longo dos tempos como um depósito de sedimentos trazidos por um arroio. Foi justamente o represamento deste arroio através da construção de uma barragem, a Barragem do Arroio Duro, que possibilitou a apropriação das terras de banhado para a agricultura. Uma grande transformação ambiental ocorreu nessa área e foi acompanhada pela população local. Um aspecto particularmente importante foi o fato dessas obras terem sido realizadas pelo poder público, representando um grande investimento de verbas públicas. Considero este o principal argumento empregado pelo governo para empreender a distribuição daquelas terras, recuperadas e usadas para agricultura.

Desde o início das discussões sobre a realização do empreendimento, as quais contaram com o empenho dos proprietários de terras da região, a questão da desapropriação e de uma possível distribuição dessas terras esteve presente. Entretanto, a implementação do programa de distribuição enfrentou intensa resistência, sendo paralisado após a primeira iniciativa abrangendo menos de $10 \%$ da área (3.645 ha). A concessão de lotes de 20 e 25 hectares ocorreu em 1962, no último ano do governo Leonel Brizola, sendo contempladas inicialmente 134 famílias. Os planos do governo e os atos e acontecimentos decorrentes de sua implementação ficaram conhecidos como Reforma Agrária do Banhado do Colégio.

Toda essa região do baixo rio Camaquã caracteriza-se, desde o início do século XX, pela produção de arroz irrigado; integrando áreas dedicadas à lavoura capitalista do arroz. Conformava, portanto, uma área de expressivo interesse, inclusive para os poderes públicos, pelo dinamismo econômico proporcionado. Esses aspectos precisam ser destacados, pois auxiliam na compreensão dos conflitos e das disputas envolvidos no empreendimento da construção da barragem no arroio Duro e, especialmente, na socialização dos benefícios promovidos por essa obra. São considerações importantes:

- terras nunca utilizadas para agricultura;

- investimento público para a montagem de uma estrutura de irrigação;

- desenvolvimento, no entorno, de uma agricultura moderna (com mecanização, irrigação, estrutura para o beneficiamento e comercialização da produção); 
- a área foi objeto de concessão aos agricultores sem terra que trabalhavam na própria região.

A apropriação do Banhado do Colégio comportou conflitos e negociações envolvendo interesses diversos e pressões de todos os tipos. Consideramos importante examinar a questão levando em conta a perspectiva dos trabalhadores rurais que reivindicaram a distribuição daquelas terras. Parte de nossa pesquisa envolveu a coleta de depoimento dos assentados, trabalhando com história oral. Apesar de conversar com vários moradores do assentamento utilizamos como critério para selecionar os depoentes, a efetiva participação no movimento de 1962, obtendo o registro oral de doze assentados.

A orientação para a análise e o trabalho com o conjunto dos depoimentos buscamos a partir de reflexões sobre o funcionamento da memória, procurando desvelar e compreender como em meio a narrativas particulares, nas quais sobressaem as interpretações e posições de cada depoente, encontramos os traços da trajetória conjunta, socialmente compartilhada enquanto experiência vivida e rememorada.

Maurice Halbwachs desenvolveu reflexões sobre a memória, problematizando a reconstrução das lembranças no âmbito das relações sociais e dos grupos de convívios. Como recordamos, este é seu foco de atenção. Em Memória Coletiva, obra inacabada, publicada pela primeira vez em 1950, esse autor revela a preocupação de compreender a memória individual considerando o indivíduo como alguém integrado em meios sociais que conformam sua percepção acerca dos acontecimentos vistos e/ou experimentados. Defende a idéia de que é como membro de grupos que recordamos. Fala em grupos de amigos, sócios, família, está pensando em grupos com variados graus de intimidade e convivência. $\mathrm{Na}$ passagem abaixo, encontramos ressaltada a necessidade de pontos de contato entre as lembranças para que ocorram as rememorações. Só podemos encontrar apoio externo, isto é, no relato dos outros, se guardamos alguma coisa das experiências compartilhadas. Ou seja, além da convivência com o grupo, é necessário que sejam compartilhadas as recordações, que estas se relacionem e se complementem.

Para que nossa memória se auxilie com a dos outros, não basta que eles nos tragam seu depoimento: é necessário ainda que ela não tenha cessado de concordar com suas memórias e que haja bastantes pontos de contato entre uma e as outras, para que a lembrança que nos recordam possa ser reconstruída sobre um fundamento comum. Não é suficiente reconstituir peça por peça a imagem de um aconte- 
cimento do passado para se obter uma lembrança. É necessário que esta reconstrução se opere a partir de dados e noções comuns que se encontram tanto no nosso espírito como no dos outros, porque elas passam incessantemente desses para aquele e reciprocamente, o que só é possível se fizeram e continuam a fazer parte de uma mesma sociedade. Somente assim podemos compreender que uma lembrança possa ser ao mesmo tempo reconhecida e reconstruída (Halbwachs, 1990, p. 34).

O que aparece como fundamental na memória individual é justamente a dimensão social. Para o autor, duas considerações são facilmente aceitas: (1) as lembranças reaparecem porque nos são recordadas por outras pessoas; (2) podemos falar de memória coletiva quando evocamos acontecimentos presentes na vida de um grupo (Halbwachs, 1990, p. 36). Porém, as preocupações do autor vão além desses casos. Podemos viver experiências sem nenhuma testemunha, isso entretanto não significa que possamos lembrar destes episódios como algo só nosso. As impressões que tivemos e que nos marcaram estão circunscritas no âmbito das relações que mantivemos, dos grupos de convívio que integramos. Sempre vivemos nossas experiências em relação com os que nos cercam e que de algum modo constituem as referências para nossas percepções. Noções e imagens que aplicamos a estas experiências são tomadas do meio social onde vivemos. É por afirmar o caráter intrinsecamente social do homem que o autor não pode senão perceber a memória pessoal apoiada na memória coletiva. Nesse sentido, podemos dizer que convivência e o diálogo são processos envolvidos no fenômeno da memória. $\mathrm{O}$ afastamento em relação ao grupo com o qual compartilhamos idéias ou experiências marca também o esquecimento e a impossibilidade de reconhecimento e reconstrução das lembranças.

A diferença entre a memória individual e memória coletiva aparece bem caracterizada em outra passagem deste autor:

No mais, se a memória coletiva tira sua força e sua duração do fato de ter por suporte um conjunto de homens, não obstante eles são indivíduos que se lembram, enquanto membros do grupo. Dessa massa de lembranças comuns, e que se apoiam uma sobre a outra, não são as mesmas que aparecerão com mais intensidade para cada um deles. Diríamos voluntariamente que cada memória individual é um ponto de vista sobre a memória coletiva, que este ponto de vista muda conforme o lugar que eu ali ocupo, e que este lugar mesmo muda segundo as relações que mantenho com outros meios. Não é de admirar que, do instrumento comum, nem todos aproveitem do mesmo modo. Todavia quando tentamos explicar essa diversidade, 
voltamos sempre a uma combinação de influências que são, todas, de natureza social (Halbwachs, 1990, p. 51).

Ressalta-se desta passagem alguns aspectos importantes na relação memória individual/coletiva como: os indivíduos recordam como membros de grupos; a memória coletiva tem por suporte o conjunto das pessoas que integram o grupo; o instrumento comum é a memória coletiva; a memória individual é um ponto de vista da memória coletiva; este ponto de vista é mutável, dependendo das relações com outros meios sociais.

A importância deste meio coletivo é destacada em outra passagem, quando relaciona a sucessão das lembranças com as mudanças nas relações com os diversos grupos de convívio:

A sucessão de lembranças, mesmo daquelas que são mais pessoais, explica-se sempre pelas mudanças que se produzem em nossas relações com os diversos meios coletivos, isto é, pelas transformações destes meios, cada um tomado à parte e em seu conjunto (Halbwachs, 1990, p. 51).

Em outro momento de suas reflexões, encontramos a lembrança como efeito de uma grande e complexa combinação de influências, afirmando, entretanto, que ao não conseguirmos estabelecer com clareza as origens destas influências, lhe creditamos um caráter independente. Este amálgama de influências sem nitidez caracteriza as lembranças. "A lembrança é em larga medida uma reconstrução do passado com a ajuda de dados emprestados do presente, além disso, preparada por outras reconstruções feitas em épocas anteriores e de onde a imagem de outrora se manifestou bem alterada" (Halbwachs, 1990, p. 71).

A convivência e a comunicação entre os membros de uma coletividade são fundamentais para a constituição desta memória coletiva. Sua duração acompanha a existência do grupo. Um indivíduo participa de diversos grupos ao longo de sua vida, cada um desenvolvendo memórias coletivas que só ao grupo interessa. Destaco uma passagem em que melhor aparece definida a memória coletiva. "E uma corrente de pensamento contínuo, de uma continuidade que nada tem de artificial, já que retém do passado somente, aquilo que ainda está vivo ou capaz de viver na consciência do grupo que a mantém. Por definição, ela não ultrapassa os limites deste grupo" (Halbwachs, 1990, p. 82). O suporte desta memória continuam sendo os indivíduos, contudo é como membros de grupos que recordam.

Em relação à história, pode-se dizer que Halbwachs emprega uma concepção muito limitada, na qual ela é apresentada como 
um quadro de acontecimentos, marcados por uma temporalidade específica, podendo fornecer apenas um quadro exterior aos grupos. Para o autor, a história começa no momento em que se atenua a memória social. Tem a preocupação de argumentar que a memória coletiva não se confunde com a história.

Maurice Halbwachs, pensador do início do século, é uma referência clássica sobre o tema da memória. Contudo a memória como foco de atenção e investigação vem ganhando, desde a década de 1980, amplo espaço nas revistas especializadas, na medida em que se afirma a História Oral como campo e método de pesquisa. Cada vez mais, os pesquisadores problematizam o trabalho com as fontes orais, emergindo entre outros pontos de reflexão, o processo da rememoração, a complexa relação com o passado que a construção das lembranças comporta. Isso tem feito com que mais e mais historiadores e cientistas de áreas afins desenvolvam um diálogo sobre a memória no trabalho de análise das fontes orais. O eixo de nossa reflexão gira em torno da idéia da memória coletiva, embora considerando algumas ressalvas aqui apenas brevemente referidas.

Na obra Memória Social, o historiador Chris Wickham e o antropólogo James Fentress fazem um alerta a respeito das proposições de Halbwachs, conforme vemos nas linhas abaixo:

[...] um importante problema que se depara a quem quer que pretenda seguir Halbwachs neste campo é elaborar uma concepção de memória que, sem deixar de prestar plena justiça ao lado colectivo da vida consciente de cada um, não faça do indivíduo uma espécie de autômato, passivamente obediente à vontade coletiva interiorizada. É por esta razão [...] que vamos usar normalmente a expressão "memória social" em vez de memória coletiva, a despeito de a segunda expressão ser mais fácil de reconhecer (Fentress, 1992, p. 7).

Com essa ressalva, não pretenderam os autores minimizar o caráter social da memória, apenas alertam para que se tenham presentes de modo mais efetivo as vinculações e relações entre essas duas dimensões - individual e coletiva - da memória, cujo suporte continuam sendo os indivíduos, pois são eles que recordam. Criticam no autor clássico a ênfase, e mesmo o que julgam ser a preponderância de uma "consciência coletiva" nos fenômenos da memória. Concordam, entretanto, com o papel essencial representado pelos grupos, o que explicitam claramente: "Halbwachs tinha por certo razão ao afirmar que os grupos sociais constroem as suas próprias imagens do mundo, estabelecendo uma versão acordada do passado e ao sublinhar que estas versões 
se estabelecem graças à comunicação, não por via das recordações pessoais" (Fentress, 1992, p. 8). Desta última consideração, dois aspectos chamam atenção, a construção de uma versão acordada sobre o passado, e a comunicação e troca como base deste processo. O papel da comunicação na construção da memória social é enfatizado por esses autores. Estão preocupados com a recordação ou o que definem como "comemoração" que é "ação de falar ou escrever sobre as recordações bem como com a reencenação formal do passado". "A experiência passada recordada e as imagens partilhadas do passado histórico" é o que lhes interessa, "pois tem efetiva importância na constituição de grupos no presente". Recordar liga-se a subjetividade, recordamos sob a forma de emoções, sentimentos ou imagens. A memória depende de encadeamentos, elos são condições para recordar.

A proposição desses autores é que devemos conciliar dois aspectos característicos da memória, o de ser um sistema de armazenamento e de registro e, ao mesmo tempo, ser ativa, isto é, podemos recuperar as informações e articulá-las de um modo novo, desenvolvendo um constante trabalho de adequação entre o presente e o passado.

Outra crítica a Halbwachs encontra-se no artigo Memória, esquecimento, silêncio, de Michael Pollak. Este autor questiona o fato de Halbwachs apresentar a memória coletiva como um fator de coesão social, enfatizando em sua interpretação uma associação entre memória coletiva e memória nacional. Pollak está preocupado com os aspetos conflituosos da memória, destacando que os trabalhos com história oral, especialmente com minorias, têm revelado a existência de "memórias subterrâneas", bem como oposições em relação a memórias oficiais, passando a visualizar disputas numa clara configuração do que chama memórias concorrentes. A partir das considerações desse autor, podemos encontrar na memória coletiva tanto fatores de estabilidade e continuidade, conforme foram enfatizados por Halbwachs, quanto elementos de conflito e disputa que conformam verdadeiras batalhas pela memória.

Essas considerações teóricas constituíram o foco a partir do qual analisamos os depoimentos. Os assentados do Banhado do Colégio, por força das circunstâncias, compartilharam um longo período de suas vidas, possuindo trajetórias semelhantes, embora não equivalentes. Trata-se de um grupo pequeno, que efetivamente teve uma experiência comum e se manteve em contato até hoje. Essa experiência transformou suas vidas e se constituiu num marco para todos. Isso vale inclusive para os que foram embora 
após terem vendido seus lotes, pois essas terras têm um grande valor e com a venda buscavam organizar suas vidas em um outro lugar. Nessa parte da pesquisa, a preocupação foi encontrar uma maneira de dar um tratamento conjunto para os depoimentos, nesse sentido falamos em termos de uma memória coletiva construída em função da experiência comum e da convivência do grupo. Estamos cientes de que particularidades e especificidades caracterizam cada depoente, mas justamente o que o conceito de memória coletiva nos instiga a perceber e a procurar é que, para além dos aspectos marcadamente individualizados de cada depoimento, existem pontos de consonância, elementos que conformam uma base comum nas rememorações. Perseguindo na direção apontada por Halbwachs, os depoimentos devem refletir, também essa base comum, aspectos complementares e consonantes.

Em relação à coleta dos doze depoimentos dos assentados convém dar algumas informações sobre o procedimento adotado. Os depoentes não foram submetidos a um questionário, muito embora tenha sido elaborado um roteiro de temas de interesse para a pesquisa, o qual orientava as intervenções quando necessárias. No princípio era explicada a proposta geral da pesquisa que estava sendo desenvolvida e era solicitado ao depoente que falasse de sua participação no movimento de reivindicação das terras do Banhado do Colégio. Nos fragmentos registrados abaixo, por opção exclusiva da pesquisadora, os depoentes não foram identificados, registrando-se somente a data da entrevista.

Ao analisarmos os depoimentos, encontramos a configuração de traços distintivos que identifica os participantes. Alguns acontecimentos tornaram-se marcos importantes no relato dos assentados, oferecendo tais experiências distinção e reconhecimento para os que delas participaram. São fatores de distinção:

- ter trabalhado nas terras do recém-esgotado Banhado do Colégio antes do movimento, seja como arrendatário, seja como meeiro em associação com os proprietários lindeiros;

- ter participado da caminhada, partindo do centro de Camaquã para o Banhado do Colégio, considerada o início do movimento de reivindicação, significando a adesão e resposta ao chamado das lideranças locais;

- ter permanecido acampado na beira do canal do arroio, pressionando o governo e esperando pela decisão a respeito da distribuição daquelas terras.

De diferentes modos, esses aspectos são referidos e enfocados, isto é, com as particularidades vividas por cada depoente nessas situações, mas aparecem sempre como elementos impor- 
tantes que demarcam a integração das experiências e dos elos compartilhados pelo grupo de assentados.

[...] é o acampamento, o pessoal fez a barraca como ele podia. Uns fizeram de lona, outros fizeram de... trouxeram madeira, fizeram de tábua, fizeram de telha, fizeram do jeito que dava [...].

Naquela época, não existia... trator era muito pouco, era carroça com tração animal.

Quando descemos de lá, a fila estava lá na faixa e a outra vinha chegando aqui... era muita, muita gente... [...].

Gente de toda redondeza... de outros municípios aí... vieram tudo... [...] esse Banhado do Colégio era muito falado... eu era muito pequeno e me lembro que o meu pai falava nele. Que tinha uma secretaria aqui em Camaquã que eles faziam inscrição pra... falavam que tal tempo iam desapropriar e tal. Mas fazia muitos anos... (29.7.1999).

Esses episódios fazem parte da memória coletiva do grupo e estão presentes em vários depoimentos, embora cada um tenha especificado de modo pessoal sua inserção e suas motivações. São marcas comuns na trajetória, elementos que identificam os participantes e são por eles valorizados.

[...] eu vim pra cá, para o Banhado, em cinqüenta e oito, aquilo era tudo virgem, banhado mesmo, não tinha nada. Eu vim para o Canjica. Então ali eu peguei a cultivar uma área lá, fiz uns trezentos hectares naquele banhado [...]. Aí continuei trabalhando na agricultura, quando em sessenta e dois começou o movimento para a reforma agrária dos sem terra..., mas a gente não acreditava naquilo que estava... o que podia acontecer com aquilo, o que é que era, o que não era... eu sei que começou o movimento. [...] nós éramos um dos líderes aí... o Epaminondas e outros daquela época, que plantavam também aí dentro já... começou porque a porcentagem era muito cara... (25.10.1999).

Terem vivido essas situações e participado dessas experiências que configuram o início do movimento, especialmente quando viviam na condição de parceiros ou, o que parece ter sido muito comum, associado a um parceiro, também aparece como fator de distinção. Como podemos ver nessa passagem sobre um dos núcleos do assentamento:

O quatro findou quase... o quatro quase vendeu tudo, o grupo quatro... tem muita pouca gente. Aquilo era gente de fora, não era gente que já trabalhava aqui dentro... aquela parte do pessoal... que vamos dizer, que se [...] no meio, que era empregado, que muitos não sabia nem trabalhar, sabia era ser mandado [...] (25.10.1999). 
O rádio foi a forma utilizada para promover o movimento e integrar um número muito expressivo de participantes.

Quando foi pra convidar ele foi na rádio Camaquense... e convidou as pessoas a participarem. Ele colocou um anúncio de meia em meia hora convidando todos que fossem sem-terra, todos os que quisessem participar. Que quisessem participar do movimento do acampamento reivindicando um lote de terra que acompanhasse ele... e marcaram... ele marcou a data e o pessoal se reuniu lá em Camaquã. (29.7.1999).

E eles que foram os que fizeram o movimento que ajudaram o Brizola... pra o povo vim, invadi como eles diziam... mas aquilo não era invasão, aquilo era... como é que era? Reforma Agrária como eles diziam... era Reforma Agrária, não era invasão...o Banhado do Colégio fazia Reforma Agrária... que eles diziam... É, e o Epaminondas chamava na rádio Camaquense, pro povo vir... (27.5.2000).

Quando os depoentes falam na trajetória de construção do assentamento, após a cerimônia de distribuição dos lotes para as primeiras 134 famílias contempladas, também foi possível perceber uma rede de temas em repetição, os quais são apresentados com particularidades e com intensidade diversas. Ressaltamos que a preocupação nessa comunicação é apenas com esses elementos comuns identificados através do conceito de memória coletiva anteriormente apresentada. Ao rememorarem a construção do assentamento encontramos narradas situações e acontecimentos que caracterizam as dificuldades enfrentadas nos primeiros anos, alguns ressaltam a solidariedade que envolveu o grupo nessa época, considerada indispensável para a sobrevivência do assentamento, como aparece nesses fragmentos de depoimentos:

Esse aí também... esse aí carregava comida pra algum agricultor que tinha ali pra baixo, que atolava, que nós não tinha estrada aqui. Ele carregava de cavalo, ele era o diretor da Cooperativa. O primeiro diretor da Cooperativa. Ele ia de cavalo levar comida pra essa gente. (30.7.1999).

[...] para ir até o Camaquã, na cidade, fazer um ranchinho de bóia, era o maior sacrifício, a cavalo ou carroça. E levava um dia inteiro pra chegar na cidade, agora, vai em dez minutos. Vai em dez minutos. Naquele tempo um colono ia na cidade de manhã cedo pra voltar de noite. Então cada um fazia o seu ranchinho, a sua nota. O vizinho que ia até a cidade, com os pobres dos cavalos no meio do barral, que nem sei. A gente encomendava um ranchinho de alimento pra ter em casa, por que era difícil. (29.7.1999). 
Aquela estrada ali não tinha, quando nós entramos aqui não tinha aquela estrada, não tinha nada... não tinha nada, nada. Aquela estrada ali foi nós que abrimos. O Vitor Queiroz tinha a última colônia, lá em cima. Então ele foi com picão e enxada, foi fazendo um trilho para ele ir de carroça pra lá... e depois lá em cima, nós ia por cima do açude da Roça Velha, assim nós fomos abrindo a estrada... nós tinha que sair por baixo, por Arambaré, pra ir a Camaquã... (17.12.2001).

Moremos embaixo de uma figueira, cozinhava na rua e dormia dentro de uma bolantinha, mas bem pequenininha... (17.12.2001).

Cada um manifestou suas impressões sobre esse tempo, diferentes ênfases foram atribuídas ao papel dos funcionários do governo e da Cooperativa nas soluções, mas as dificuldades desses primeiros anos aparecem de alguma forma referidas em todas as narrativas. Trata-se de outra experiência valorizada na memória do grupo.

As perseguições e temores vividos após o golpe militar de 1964 é outro tema integrando a narrativa dos assentados. As relações entre o Movimento dos Agricultores Sem Terra (MASTER) e o PTB contribuíram para gerar um clima de instabilidade no assentamento logo após a instalação da ditadura. Ao abordarem esses temas, além de contarem sobre vivências pessoais, lembrando situações enfrentadas com a polícia ou com os administradores do assentamento, é comum relatarem situações vividas por companheiros, sobre as quais ouviram falar ou testemunharam. As prisões, perseguições e o isolamento por força das acusações e desconfianças difundidas foi a experiência que passaram a viver dentro do assentamento.

Em sessenta e quatro deu aquele reboliço com o Brizola, fugiu, aquela coisa, aí nós tivemos ameaçados de findar com isso aqui e tirarem nós tudo daqui... mas por causa da cooperativa é que não saiu, não conseguiram tirar, ficamos aí. (25.10.1999).

Tem muita gente que vamos dizer, que ganharam o terreno e não ganharam a terra, então tem alguns aí ainda, morando, que não ganharam terra, a colônia, vamos dizer, só ganharam um terreno, esperando a segunda remessa, ou a terceira, e isso não chegou nunca. E estava pronto tudo, estava tudo programado para ter continuação isso aí, mas depois da revolução de 64, ai findou, não teve mais, parou tudo... mas eles estão aí morando até hoje, esperando, para ter uma colônia, aí... fracassou, fracassou mesmo... (25.10.1999).

[...] eles prendiam, prenderam todos... a revolução aquela que deu, aí eles prendiam os outros companheiros dele, que participaram 
nesse movimento, eles prenderam. Tudo foi preso pra Porto Alegre, tiveram com 50. [...]. Aí graças a Deus ele conseguiu sair da cadeia, mas ele foi preso várias vezes, por causa desse movimento, eles prendiam... largavam e prendiam de novo [...]. (29.7.1999).

Não tinha título definitivo, mas tinha o título de posse. Ai começou a pressão lá com o presidente da República pra tirar a área toda, eram quarenta e não sei quantas mil hectares. Até que estourou lá... estourou e fiquemos todo quebrado da mão, e agora? Não sabia se não iam corrê com a gente. Naquelas horas tu... o exército derrubou com o Presidente da República, podia corrê nós tudo daqui. Não se sabia o que ia acontece. Mas foi indo, foi indo... foi passando. (30.7.1999).

[...] mas a minha prisão foi só até Camaquã, eu tive em Camaquã, não fui para frente. Porque ele pegou, ele chamava essas gente grande da cidade, para vir ver se aquele cara era comunista. Quando eu tava preso, veio um conhecido, que eu trabalhava com eles ali pra baixo, trabalhei anos com ele [...]. Gente boa, muito contra aquilo, mas era uma gente boa. Ai vieram, quando entrou um, diz oh! diz - olha tu tá ai também! [...]. Aí disse pro delegado - não, esse ai é gente boa, esse não tem nada de comunista, essa gente querem é trabalhar. Foi que me largaram (30.7.1999).

Eles chegaram a tomar minha colônia e contempla outro com a minha colônia, enquanto eu estava fugido. Ai então o cara assumiu a colônia e eu mandei um recado pra ele. Mandei alguém dizer pra ele: Olha diz para o fulano que eu vou voltar e eu vou assumir a lavoura do jeito que ela estiver, pode tá cheia de planta, eu vou assumir, não deixem ninguém entrar. (5.5.2000).

Nem tudo é revelado e, de certa forma, é o conjunto dos depoimentos que esclarece alguns episódios, oferecendo perspectivas complementares. Foram tempos de insegurança que ganham forma através da lembrança dos assentados. Constitui outro elo entre o grupo, uma experiência lembrada com pesar, mas mesmo assim extremamente valorizada nas rememorações. Em todos os depoimentos aparece alguma forma de reconhecimento pelo empenho político do governador Leonel Brizola em realizar a reforma agrária no Banhado do Colégio, embora todos reconheçam seu caráter incipiente e inacabado.

Os resultados do trabalho árduo é outro aspecto ressaltado, a melhoria aparece associada com a construção de uma moradia melhor ou com a compra de um trator para o trabalho. A prosperidade do grupo é expressa através do fato de que, após acordo governamental estabelecido em 1972, conseguiram pagar o financiamento concedido para a quitação da terra. Encontramos tempos 
de prosperidade identificados e relatados de diversas maneiras pelos depoentes, expressando a dedicação ao trabalho, a riqueza das terras recebidas, a fartura das colheitas.

Além dessa rede temática presente de diferentes modos nos depoimentos sobre o movimento de conquista das terras do Banhado do Colégio, as dúvidas e pontos que permanecem obscuros na opinião dos assentados tornam-se focos de conflitos e disputas. Um ponto polêmico é o processo judicial que durou dez longos anos. A maioria deles não sabe exatamente quais foram as suas resoluções. Alguns expressam perplexidade, perguntando como os proprietários provaram a propriedade sobre as terras do banhado, como obtiveram os documentos e o reconhecimento, pois as escrituras que receberam na década de 1970 foi passada pelos fazendeiros.

Meia... plantava à meia. Aí os fazendeiros viram que produzia muito milho, começaram ... a invadir... arrendar... e aí que foi que tomaram conta. Aí tomaram conta... se dividiram e tomaram conta. (30.7.1999).

[...] não sei como, sei que fizeram um acordo com o governo, nós também ficamos sossegados dentro, nós vivíamos sempre ameaçado aqui, de ser corrido, nós ficamos... Pegamos a escritura, pagamos, ninguém perdeu nada, o proprietário que se fazia proprietário ganhou o dele e nós ganhamos a nossa terra e continuamos trabalhando, até hoje, só pena não ter continuado isso aí. (25.10.1999).

E eles ajeitaram uma meia-dúzia aí, só queriam a escritura pra ser dono do seu nariz... até hoje não era pra existir escritura de nenhum... [...] ... era pra ser do Governo. O cara não podia vender, o cara não podia vender se não tivesse as escrituras... ia passar pro filho ou pra outro, mas vender não podia... isso era o certo... até hoje, ninguém era pra ter escritura [...]. Mas ajeitaram uma meia-dúzia aí [...]. Ah não... queremos a escritura, queriam escritura, por que queriam escritura, pra ser dono das terras... Aí, ganharam as escrituras, já foram vendendo... alguns já... que não tinham vontade de trabalhar mesmo... a maioria ficou aqui... (27.5.2000).

Outra questão presente praticamente em todos os depoimentos refere-se ao conflito com os fazendeiros. Em alguns depoimentos esses litígios aparecem minimizados, ficando, inclusive, enfraquecidas as posições e atitudes dos fazendeiros contra a distribuição das terras. Em outros, as relações com os fazendeiros são relembradas como fonte de informação sobre a real situação das terras do banhado, ou seja, conversas com proprietários da área estariam na origem da afirmação de que o banhado não tinha 
dono. A maioria dos depoentes revelou algum tipo de relação com os fazendeiros da região, seja como empregado, como parceiro ou mesmo como arrendatário. Alguns dizem ter recebido apoio do patrão para participar do acampamento; outros afirmam que foram avisados de que aquelas terras não eram de ninguém; outro diz que seu patrão o alertou de que "dali sairia alguma coisa". Estranhamente, parecem esquecer que os fazendeiros entraram na justiça contestando a desapropriação da área. A pesquisa nos jornais da época e os discursos na Assembléia Legislativa revelam um clima muito tenso, aparecendo o registro de que os fazendeiros estavam dispostos a defender com armas, se necessário, o respeito à propriedade. $\mathrm{O}$ temor em relação à mobilização dos agricultores sem terra está presente nos discursos dos representantes dos proprietários e nas matérias jornalísticas. No entanto, o papel dos fazendeiros é lembrado com certa ambigüidade, o que pode ser associado com situações posteriores que implicaram uma aproximação e afirmação de interesses comuns. Como vimos anteriormente, a adequação entre o presente e o passado através da rememoração é uma característica importante do trabalho da memória. Desde os anos oitenta, uma associação integrando fazendeiros e assentados - Associação dos Usuários da Barragem do Arroio Duro - controla a distribuição de água para a irrigação na área.

As colocações realizadas nesta comunicação estão longe de esgotar o tema, apontamos e exploramos de modo sintético algumas questões relevantes que, para o caso estudado, podem ser tomados como formadores de uma memória que é apropriada e compartilhada e se faz presente nos relatos dos assentados.

Neste trabalho partimos da consideração de que, para além de todas as informações passíveis de serem obtidas num depoimento, da subjetividade revelada, da valorização das experiências vividas, é a própria rememoração do passado e os usos desse passado na dinâmica social um ponto importante na pesquisa com história oral. É a experiência do indivíduo com o passado que precisa ser compreendida, o que implica termos em conta o trabalho da memória. Foi sob o peso das considerações sobre a memória e as lembranças que examinamos esses depoimentos. 


\section{Referências}

FENTRESS, James; WICKHAM, Chris. Memória social. Lisboa : Teorema, 1992.

HALBWACHS, Maurice. A memória coletiva. São Paulo: Vértice/Editora Revista dos Tribunais, 1990.

POLLAK, Michael. Memória, esquecimento e silêncio. Estudos Históricos, Rio de Janeiro, v. 2, n. 5, 1989. 